\title{
Derivations and Complexity Filters
}

\author{
Hilda Koopman
}

UCLA

\section{Introduction}

In Koopman and Szabolcsi ${ }^{1}$ 2000, henceforth K\&Sz, we account for the different word order and constituency of verbal complexes in Hungarian, Dutch and German by a derivational theory which relies on overt (remnant) XP movement only. The derivations yield paradigms that are not always attested in full in a particular language: there are language specific gaps in the paradigms. K\&Sz argue that these gaps should be accounted for by a new brand of filters, complexity filters, which act on the representations that the derivations generate. Complexity filters are sensitive to overt material only, and impose restrictions on the "size" or "internal complexity" of certain constituents in designated Spec positions at the end of the derivation. This paper establishes the need for complexity filters, drawing heavily on $K \& S z$, discusses particular filters and the phenomena that they capture, as well as general issues surrounding this type of filter.

\section{Verbal complexes: The Koopman and Szabolcsi proposal}

K\&Sz deal with the analysis of the order and constituency of verbal complexes in Hungarian, Dutch and German. The examples in (1) contain a sequence of infinitives in Dutch and German, and illustrate representative strings of the major word order types: inverted orders (3-2-1), English orders (1-2-3), and climbing orders (3-1-2). The verbs that participate in these verbal complexes have been called restructuring verbs or verb raising verbs depending on the linguistic traditions and the language family. In the examples below, VM refers to "verbal marker", a cover term used in the Hungarian tradition for small clause predicates. The numbers represent the hierarchical structure given by selection, with 1 the highest ${ }^{2}$.

(1) a. Inversion: German dass ich Maria anrufen können willVM4 $\mathrm{V}_{\mathrm{inf}} 3 \quad \mathrm{~V}_{\mathrm{inf}} 2 \mathrm{~V}_{\mathrm{f}} 1$ that I Mary up-call.INF can.INF want

b. English order: Dutch

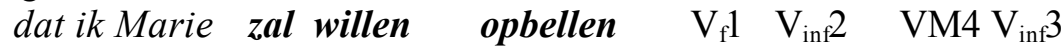
that I Mary will want.INF up-call.INF

c. VM climbing: Dutch (dat ik) Marie op zal willen bellen $\quad \mathrm{VM} 4 \mathrm{~V}_{\mathrm{f}} 1 \mathrm{~V}_{\text {inf }} 2 \mathrm{~V}_{\text {inf }} 3$ (that I) Mary up will want.INF call.INF

On the basis of Hungarian verbal complexes, K\&Sz show that (1a) and (1c) cannot be derived by head movement, but must be derived by (remnant) phrasal movement. K\&Sz furthermore establish that Hungarian surface strings like (1b) do not correspond to a base generated order either. Intermediate infinitives can be topicalized, a phrasal property, without their complements. If intermediate infinitives can be moved as remnant XPs, the derivation of such strings must involve a stage at which intermediate infinitives are phrasal remnants. Thus, all orders in (1) involve derivations creating phrasal remnants, and remnant movements. $\mathrm{K} \& \mathrm{Sz}$ develop a unified remnant movement analysis for these verbal complexes: each surface string is 
derived by the same (phonologically) overt (remnant) XP movements. Depending on how overt material gets carried along ("pied-piped") or separated ("split") in the course of the derivation, different surface orders and constituencies obtain. As a result of the derivations, surface representations vary in precise ways with the type of derivation, and the length of the derivation, in particular with the number of cycles. One might wonder if these surface representations serve any other purpose. We argue they do: they provide the vocabulary for filters that exclude certain ungrammatical patterns which are surprising from a language internal point of view, from a crosslinguistic point of view, as well as from a theoretical point of view. Once the need for these filters established, I will show that their effects are ubiquitous. .

\subsection{Explaining the derivations: the structure and the players}

Since all orders are derived by remnant movement, large structures are necessary, so as to allow the creation of the relevant XP remnants. Rather than view large structures as inherently problematic, we exploit them, and argue that they allow for a simplification of the computational system. Basic movement operations can be simplified, and automaticized. Movement is XP movement only ${ }^{3}$, it is feature driven, and of overt phonological material only (as in Kayne 1998). Movement is not subject to economy conditions: the computational system is blind and fully automatic. Different surface patterns result from the particular history of the derivation: which parts of the structure may be split (expressed by language specific "splitting" parameters), and what "size" constituent is allowed to occupy a particular Spec position at the end of the derivation (expressed by language specific complexity filters). Splitting parameters and complexity filters are independent, but in many cases interact to restrict what size constituent can be pied-piped, and what parts of the structure must be "chopped up" into smaller pieces. Large structures are not only unavoidable, but empirically desirable: they allow for a substantially broadening of syntax (the syntax of morphology can be incorporated quite nicely), and for insights in the nature of crosslinguistic variation. Large structures can be viewed as being constructed out of many small identical repeating structures, little cycles. In each of these cycles, a series of identical movements takes place ${ }^{4}$.

The remainder of this section rapidly introduces the background that is necessary to focus on how representations underlying the inverted, climbing and English orders vary at the end of the derivation, and how complexity filters are sensitive to these representations. For more extensive discussion, and spelled out derivations, the reader is referred to K\&Sz 2000.

\subsubsection{The structure of an Infinitival CP.}

We roughly assume the structure below for an infinitival CP. (For simplicity, I have omitted PredP, a projection between CP and InfP. PredP attracts VP+). Each projection has a Spec position and a head position, which is omitted in the structures below for ease of exposition, unless it contains some overt material. Structures are universally unidirectional, as in Kayne 1994. 
(2)

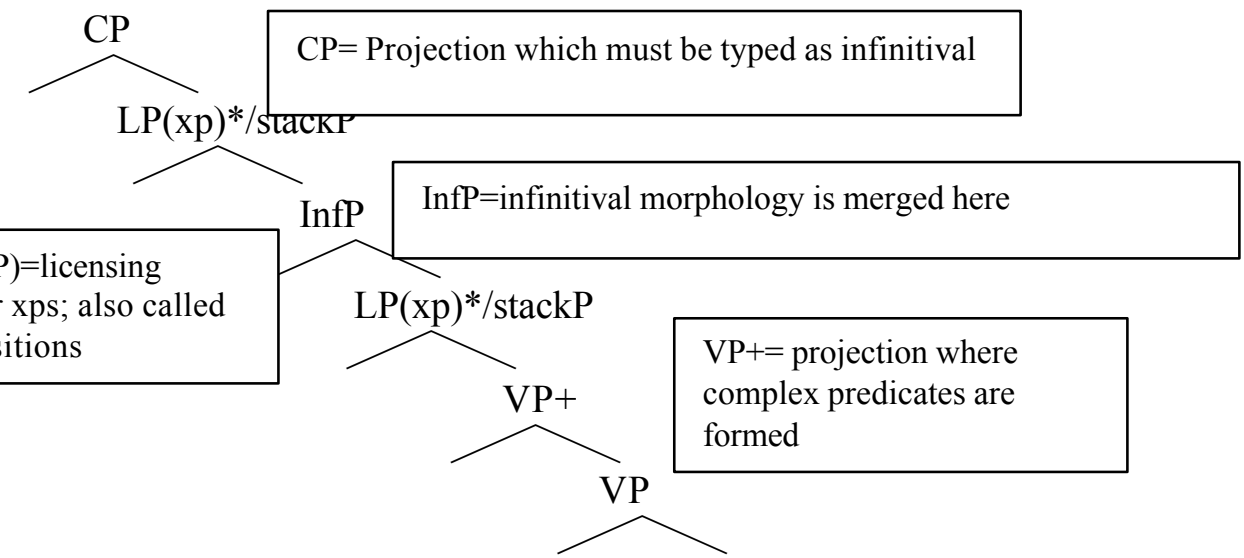

Thus:

- Every VP is dominated by VP+, where complex predicate are formed. (see 2.1.2)

- Every VP+ is dominated by licensing positions for XPs, (LP(xp)), also referred to as StackPs by K\&Sz. StackPs ${ }^{5}$ are interspersed throughout the structure (see K\&Sz for more discussion).

- Movement of XPs to LPs/stackPs creates remnant VP+s or remnant phrasal categories. more generally.

- Infinitival morphology is introduced in InfP: InfP attracts some (phrasal) projection containing $\mathrm{V}$.

- All infinitival complements are CPs.

- A projection containing InfP needs to move to CP to "type" the CP as infinitival. This in turn will enable a higher selector to satisfy its relevant c-selection feature.

Within infinitival complements, a series of movements must take place from bottom to top:

(3) VM (=small clause predicate $)$ to VP+ $\mathrm{XP}$ to $\mathrm{LP}(\mathrm{xp})$

$\mathrm{VP}($ or $\mathrm{VP}+$ ) to InfP

for complex predicate formation

for XP-licensing

for inflection on $V$

InfP to CP

to "type" CP as infinitival

\subsubsection{VP+: the location of complex predicate formation.}

Complex predicates are established in the following configuration (VM represents different small clause categories; VP+ and VP are two different projections; the head position of VP+ is systematically omitted):

(4)

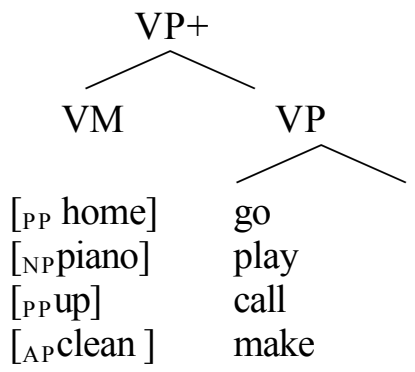


All possible categories of small clauses are represented in (4), except for verbal small clauses. $\mathrm{K} \& \mathrm{Sz}$ argue that restructuring verbs form complex predicates with verbal small clauses, and attract not a VP, but a VP+ of the form in (4). Restructuring verbs thus obligatorily and universally form a substructure of the type illustrated in (5) in the course of the derivation.

(5) Restructuring verbs require of carrier with a $V P+$ feature in Spec, $V P+$ :

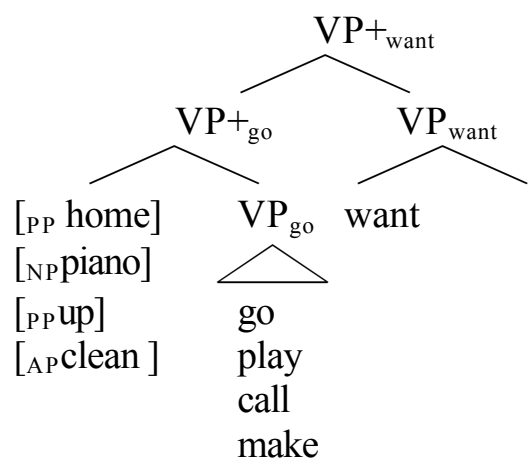

The distribution of small clauses is thus an essential part of restructuring paradigms, by virtue of (5). This is a crucial difference from other proposals which in essence treat restructuring separately from other small clause predicates.

Given the players, and the structure, some restricted variation in pied-piping and splitting is responsible for different orders. $\mathrm{VP}+_{\text {go }}$ could have extracted from the complement, yielding (5), or $\mathrm{VP}+_{\mathrm{go}}$ could have pied-piped some other category, with its own licensing requirement, as in (6).

(6) The attracted $V P+$ pied-pipes $X P$;

$X P$ may have its own licensing requirements:

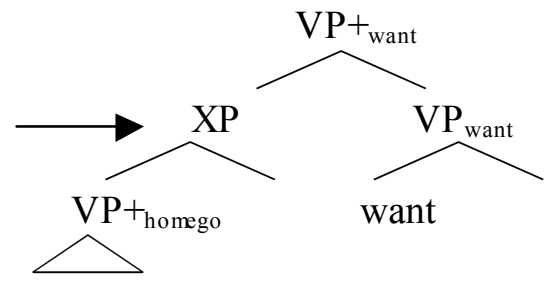

home go

(5) results in inverted (3-2-1) or climbing orders (3-1-2). If XP equals CP, (6) results in English orders.

VP and VP+ enter into different relations. VP is attracted by InfP: if VP pied-pipes VP+ inverted orders obtain, if $\mathrm{VP}$ does not, but splits out of $\mathrm{VP}+, \mathrm{VP}+$ is a remnant, and climbing orders result (see section 2.1.3). VP+ itself will be attracted by a higher restructuring predicate, and will extract as VP+ or pied-pipe some other category (see section 2.2). Schematically: 


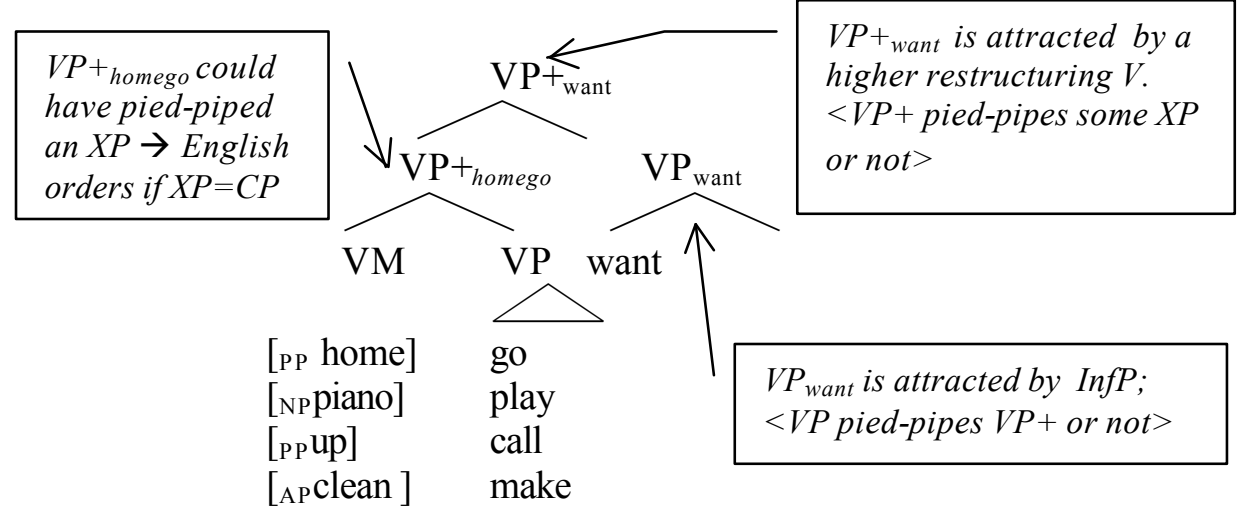

\subsubsection{How the verb gets infinitival inflection}

Depending on whether VP or VP+ combines with infinitival morphology or not, climbing orders (4-1-2-3) or inverted orders (4-3-2-1) result. K\&Sz assume that the verb and the suffix combine not by head movement but by remnant XP movement. Either remnant VP+ or remnant VP movement yields the desired linear string with $\mathrm{V}$ preceding the infinitival morpheme -en. However, VP+ or VP movement will yield different surface constituency (nodes containing overt material are boldfaced), as shown below:

(8) a.

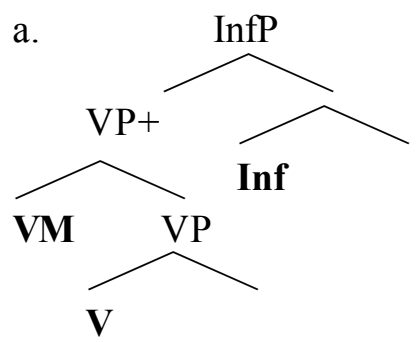

b.

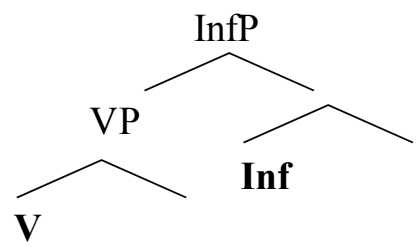

The two options are in fact part of the grammars of Hungarian, Dutch and German. In German, the unmarked case is movement of VP+ for infinitival morphology, in Dutch, movement of $\mathrm{VP}^{6}$.

(9)

(Remnant) $V P+$ moves to InfP $\rightarrow$ inversion

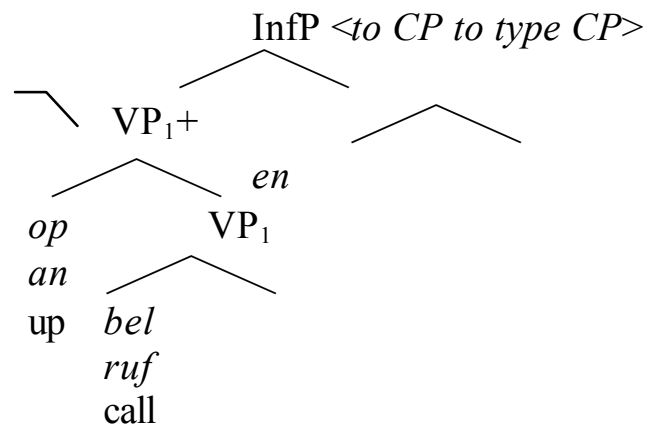

Since the infinitival morpheme cannot be stranded ${ }^{7}$, the InfP constituent in (9) is frozen; VP+ will pied-pipe InfP to satisfy other restructuring predicates, and InfP will have to move to $\mathrm{CP}$ to type $\mathrm{CP}$. In other words, InfP carries out the tasks of both VP+ and InfP. 
If VP splits out of VP+ and moves to InfP, a different surface structure results:

(10) VP splits out of $V P+$, and moves to InfP: $\rightarrow$ Dutch infinitives, Hungarian neutral sentences);

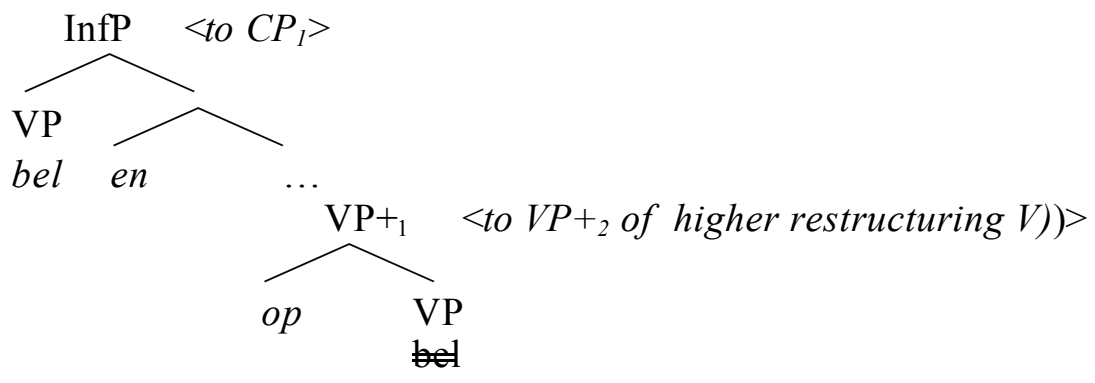

In this structure, InfP and VP+ each do their won business. In particular, VP+ will move to satisfy a higher restructuring predicate, and will distribute as the $\mathrm{VP}+$ of that predicate. InfP will move to $\mathrm{CP}$ (to type the infinitival), and hence distributes as $\mathrm{CPs}$ do.

\subsubsection{What happens when a restructuring predicate is merged next?}

Suppose that, after completion of the infinitival cycle, a restructuring verb is merged. The restructuring verb checks that it selects for the right type of category (in this case an infinitival $\mathrm{CP}$ ). It attracts a carrier of an (active) $\mathrm{VP}+$ feature, i.e. the $\mathrm{VP}+{ }_{1}$ inside the infinitival $\mathrm{CP}$.

(11)

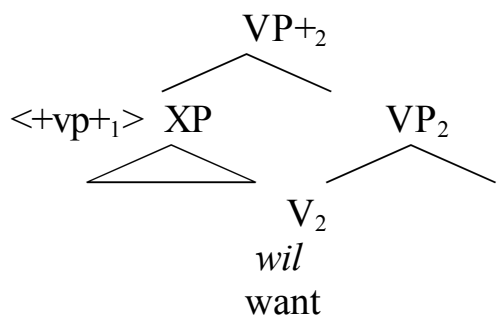

In this configuration, the $<+v p>$ feature deletes (i.e. it can be used only once).

Given the options for infinitival morphology outlined above and general pied-piping conventions, there are now three different candidate structures that can satisfy the needs of the restructuring verb. These are exemplified in

(12), (13), and (14) respectively. Each of these will result in a different surface order and constituency. 
Inversion: (remnant) $V P+{ }_{1}$ with $<v p+>$ feature pied-pipes InfP, InfP extracts out of $\mathrm{CP}$ to $\mathrm{VP}+{ }_{2}$ :

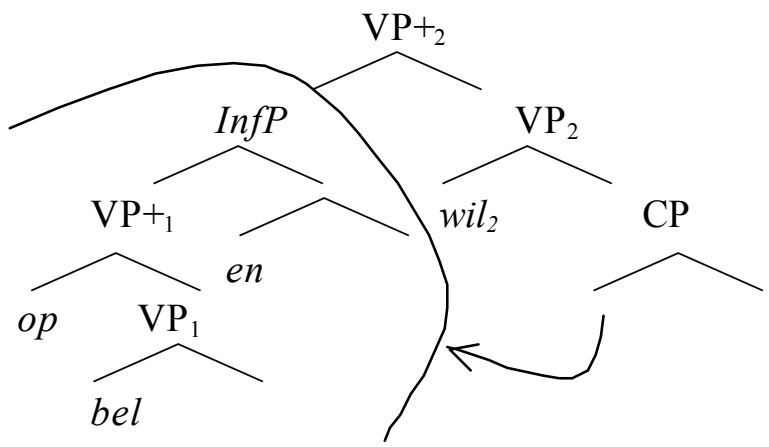

This will yield inverted strings (Dutch: opbellen wil or German: anrufen wil)

$$
\text { Climbing: (remnant) } \mathrm{VP}+_{1} \text { extracts from the infinitival } \mathrm{CP} \text { to } \mathrm{VP}+{ }_{2}
$$

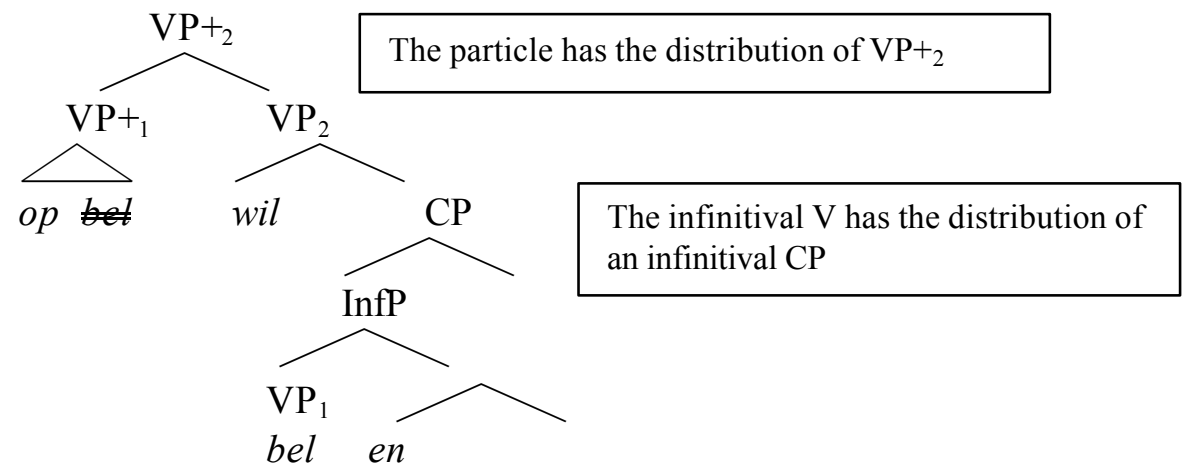

This derivation yields climbing orders: the particle or the small clause predicate "climbs", and the infinitive distributes like a CP: op wil bellen $=\left[{ }_{V P+}\right.$ op ${ }_{\text {wil }}$ [CP bellen].

(14) English orders: $V P_{1}+$ with the $<v p+>$ feature pied-pipes InfP and $C P$; $C P$ moves to $L P(x p)$ :

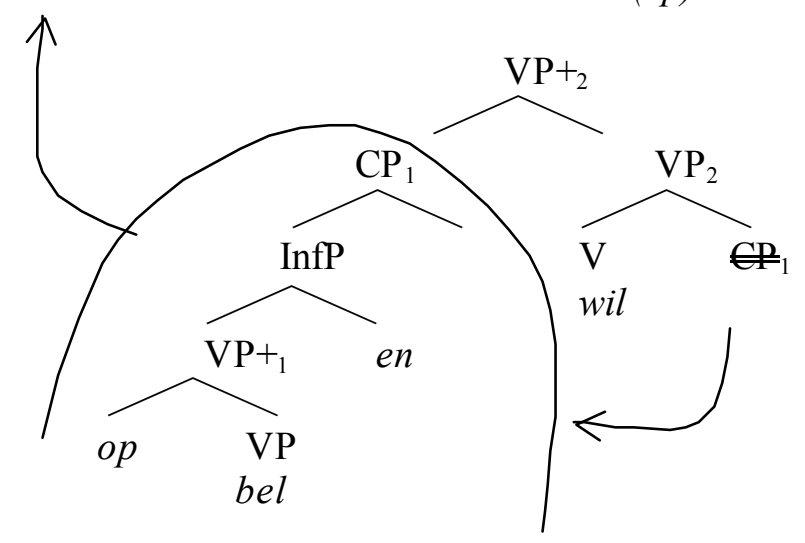


This derivation underlies English orders (wil opbellen). CP moves out of Spec, VP+ to LP(cp), since it needs to be licensed as a CP. This movement results in a $\mathrm{VP}+{ }_{2}$ structure in which $\mathrm{VP}+{ }_{2}$ contains no overt phonological material at all, as shown below:

(15) Representation after CP movement (extraction from Spec, $V P+$ to $L P(x p)$ ):

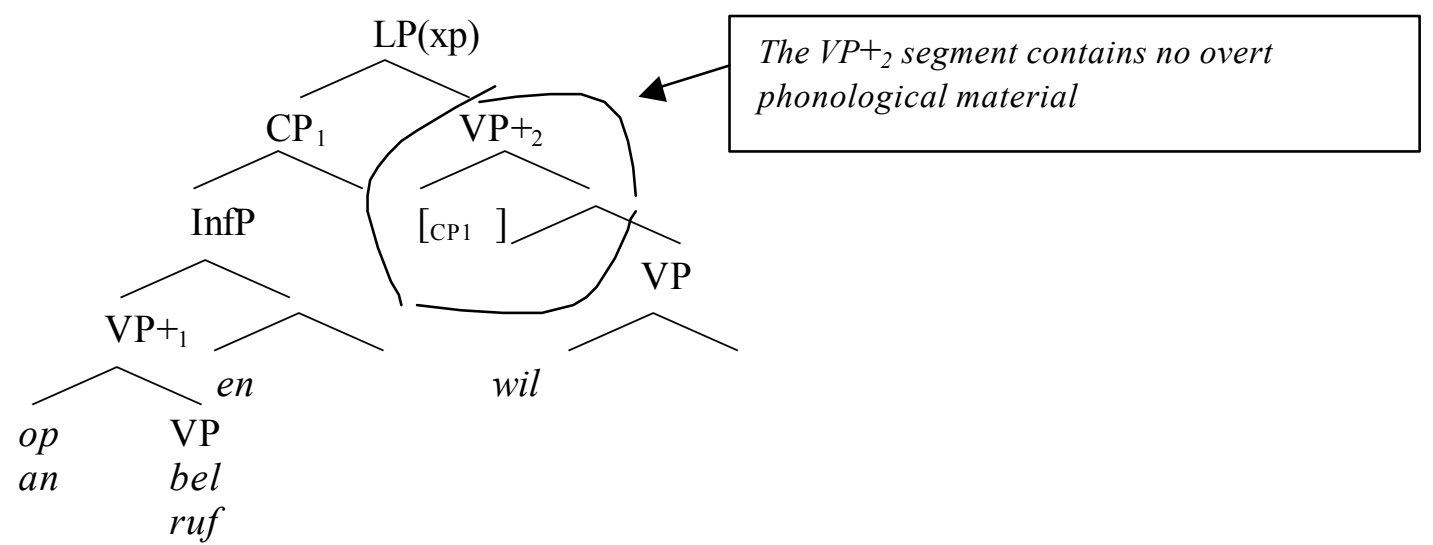

2.2 VP+ varies in complexity depending on the derivation.

These derivations lead to the following observations:

(16) The "complexity" of the internal structure of VP+ varies in very precise ways, depending on the history of the derivation.

First, it varies as to whether or not there is overt material in VP+ at the end of the derivation (climbing and inversion versus English orders). Secondly, when VP+ contains overt material, it varies as to how much structure dominates the overt material (inversion>climbing), and what exact categories dominate overt material in Spec, $\mathrm{VP}+$. In inverted structures, Spec, $\mathrm{VP}+{ }_{2}$ contains an overt VM, V and Inf. In terms of structure dominating the most deeply embedded overt material in $\mathrm{VP}_{1}, \mathrm{VP}+_{2}$ is separated from $\mathrm{V}_{1}$ by the categories $\mathrm{VP}_{1}, \mathrm{VP}_{1}+$, and InfP. This is the "heaviest" and most complex $\mathrm{VP}+{ }_{2}$ of the three structures under consideration ${ }^{8}$.

Inversion:

Complexity of Spec, $V P_{2}$ : categories dominating the most deeply embedded overt material $<V P, V P+$, InfP $>$ )

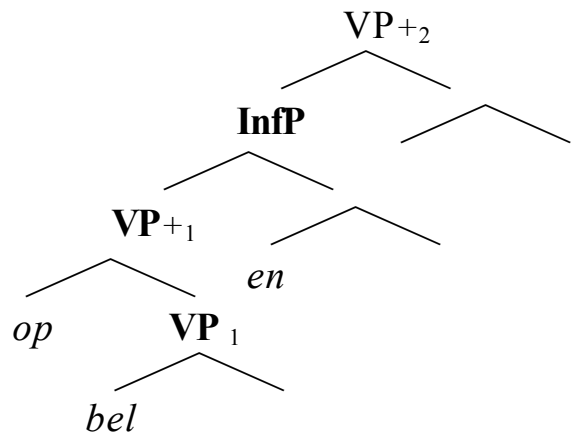


In the climbing case, only the XP in Spec, $\mathrm{VP}+_{1}$ contains overt material, since the verb has moved out of the constituent. In terms of structure dominating overt material, $\mathrm{VP}+_{2}$ contains $\mathrm{PP}$, and $\mathrm{VP}+{ }_{1}$. Therefore, it is structurally less complex than the $\mathrm{VP}+{ }_{2}$ in the case of inversion.

Climbing : Complexity of Spec, $V P_{2}$ : categories dominating the most deeply embedded overt material $<P P, \quad V P+_{1}>$

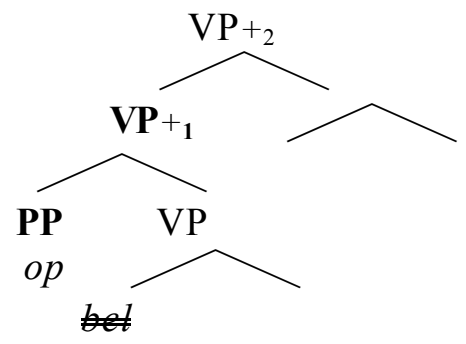

In English orders, $\mathrm{VP}+{ }_{2}$ contains no overt material, because $\mathrm{CP}$ has extracted from $\mathrm{VP}+$. Since there is no overt material at the end of the derivation, $\mathrm{VP}+{ }_{2}$ has zero complexity:

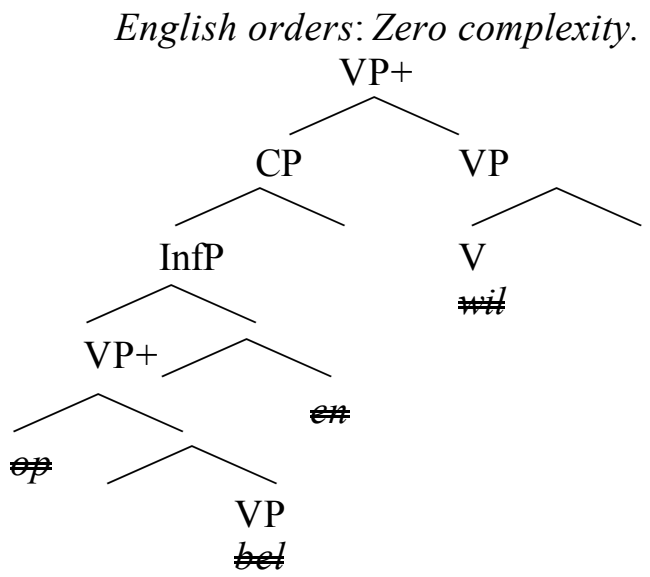

The complexity of a constituent in a particular designated position (here $\mathrm{Spec}, \mathrm{VP}+{ }_{2}$ ) is a matter of depth of embedding (the number of nodes separating overt material from the designated node $\left(\mathrm{VP}+{ }_{2}\right)$, as well as the type of categories dominate the overt material. This leads to the following generalizations:

(20) Order of complexity of VP+ decreases in specific ways:

Inverted orders (3-2-1) >climbing orders (3-1-2) $>$ English orders (1-2-3).

(21) Spec, $\mathrm{VP}+$ contains different categories dominating overt material:

Inverted orders (InfP, VP+, VP) Climbing order (VP+, XP), English order (0)

Moreover, as a function of the derivations, complexity increases with the number of cycles in inverted structures and climbing structures, but stays constant in English orders. This is briefly illustrated in the following section for inverted, climbing and English orders respectively. 
2.3 Complexity of VP+ increases with the number of cycles for inverted and climbing orders, but nor for English orders.

Once the derivation has reached the stage in

(12), the following sequence of movements takes place within the infinitival CP (see (3)):

(22) (remnant) VP+ moves to InfP to get inflected;

XPs move to LP(xp)

(remnant) InfP moves to $\mathrm{CP}$ to type $\mathrm{CP}$ as infinitival

XPs move to LP(xp)

Next, a second cycle starts with the merger of a second restructuring verb. Restructuring verbs form a complex predicate by attracting a VP+ constituent with $a<v p+>$ feature. (They also check independently that they have an infinitival CP complement). The relevant VP+ extracts from the infinitival $\mathrm{CP}$ and pied-pipes InfP to $\mathrm{VP}+$. This yields the $\mathrm{VP}+{ }_{2}$ below:

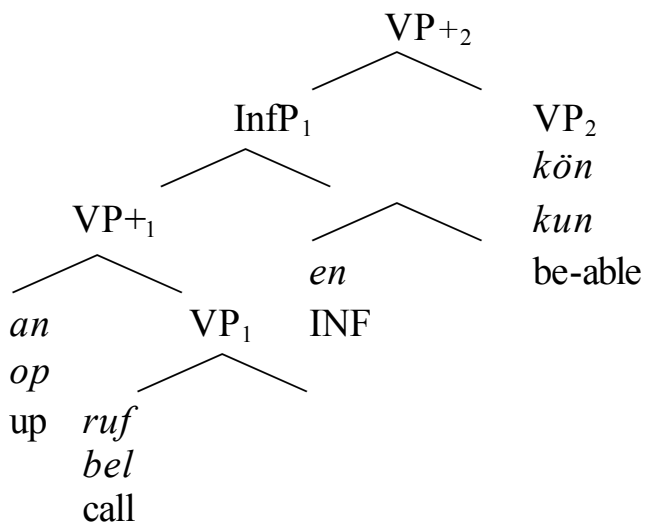

If this $\mathrm{VP}_{2}$ is contained in an infinitival clause, $\mathrm{VP}+{ }_{2}$ moves to InfP get inflected, and $\mathrm{VP}+{ }_{2}$ will subsequently pied-pipe InfP in the other tasks that VP+ must perform:

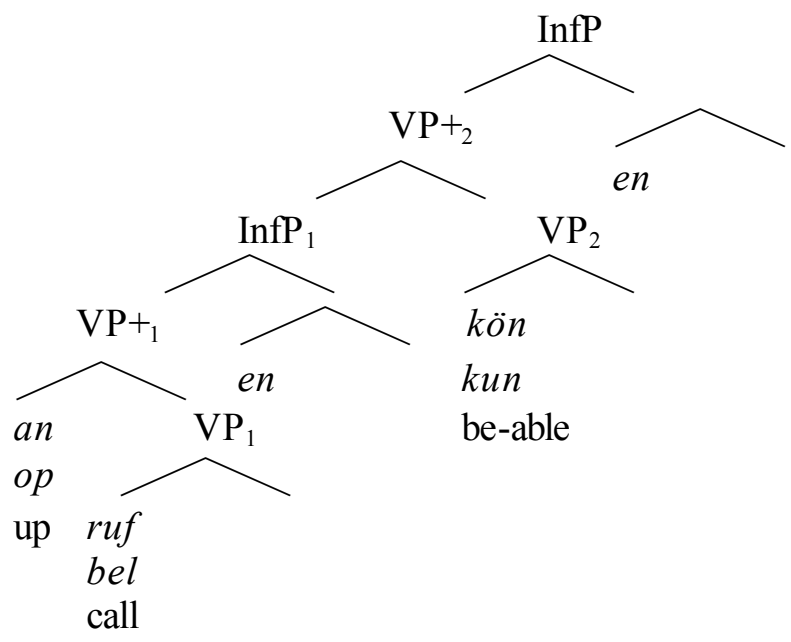

Adding a third restructuring verb and extracting the $\mathrm{VP}+{ }_{2}$ from $\mathrm{CP}$ adds further structure and overt material to $\mathrm{VP}+_{3}$ of the third restructuring verb, thus further embedding the lowest infinitival: 


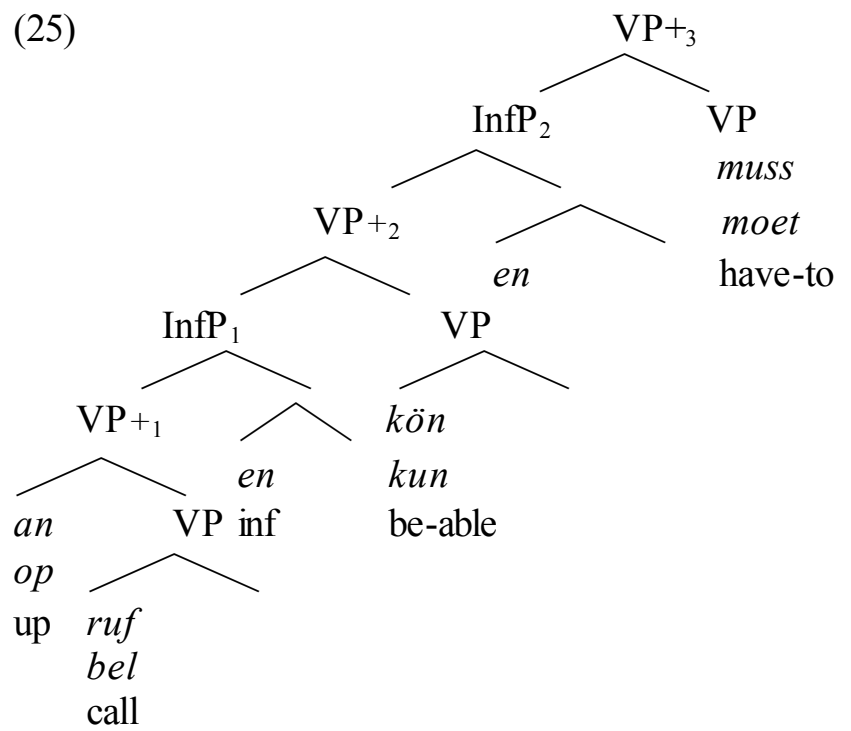

Inversion therefore yields maximally complex $\mathrm{VP}+\mathrm{s}$. The complexity grows with the length of the derivation (i.e. with the number of CP cycles), both in terms of the number of nodes dominating the most deeply embedded overt material, and in terms of the categories dominating the most deeply embedded categories: $\operatorname{InfP}_{1}$ is more deeply embedded in (25) than in (23).

Climbing structure also grow in complexity with the number of cycles; yet fewer nodes and fewer types of categories dominates the most deeply embedded overt material than in the climbing case (InfP is outside VP+, since VP moves to InfP). In the second cycle VP+ has the following structure:

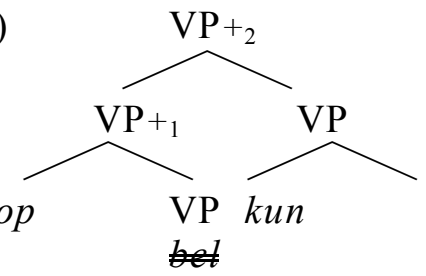

Adding a third restructuring verb, and extracting $\mathrm{VP}+{ }_{2}$ from the infinitival $\mathrm{CP}$ yields a $\mathrm{VP}+{ }_{3}$ of the following shape at the end of the derivation:

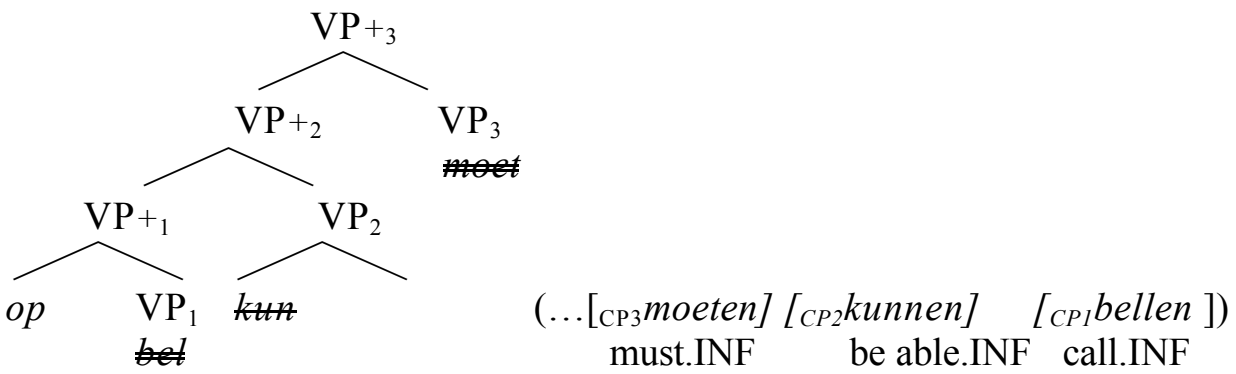

In the English orders, VP+ does not grow in complexity at all: at each cycle VP+ contains a trace of the $\mathrm{CP}$ that has moved out of $\mathrm{VP}+$. Since there is no overt material in $\mathrm{VP}+$, the complexity measure is null, and remains null. It simply is irrelevant that the $\mathrm{CP}$ trace itself becomes more complex. 


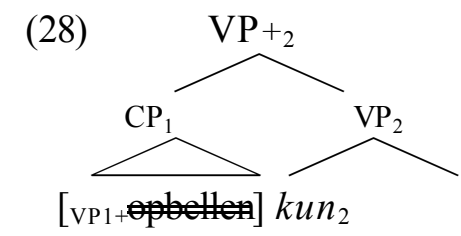

$$
\text { (...[CP1 opbellen ]) }
$$

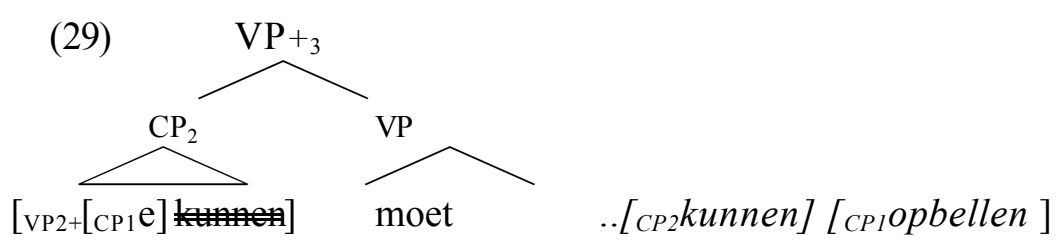

\section{Does UG care about complexity? The case of Dutch infinitives.}

As a consequence of the derivations, the internal representations of the different $\mathrm{VP}+\mathrm{s}$ vary in very precise ways at the end of the derivation. They differ in internal complexity, where the internal complexity varies as a function of the length of derivations:
a. Order of complexity from greatest to least:
inversion $>$ climbing $>$ English order
b. Number and types of of different categories dominating overt material inversion $>$ climbing $>$ English orders
b. Complexity increases with the number of cycles, in the inversion and climbing cases, but not in the English orders.

Does UG care about complexity of this type? If it does, what type of phenomena would we expect to find in natural languages? If languages care about internal complexity in designated positions, grammaticality judgments should depend on the length of the derivation in inversion or climbing cases, but not in English orders. Moreover, such cases should resist alternative explanations, be it in semantic, syntactic, morphological, or prosodic terms. It turns out that the distribution of Dutch infinitives in verbal complexes exactly fits the bill ${ }^{9}$. Dutch imposes an upper bound on complexity on infinitives in inversion and climbing cases, but not in English orders. This restriction can be expressed as a filter, which sets an upper bound on allowable complexity on infinitives in VP+.

\subsection{Dutch (restructuring) infinitives.}

Besides the generally possible English (CP-pied-piping) orders, Dutch also allows for inversion of infinitives (InfP extraction):
(31) a.
dat ik vandaag wil schilderen that I today want paint.INF
$\mathrm{V}_{\mathrm{f}} 1 \mathrm{~V}_{\text {inf }} 2$
b. dat ik vandaag schilderen wil that I today paint.INF want 'that I want to paint today'


The inverted infinitives have the same properties as inverted infinitives in Hungarian or in German: in particularly, they can be fronted. This is a diagnostic property of inversion: ${ }^{10}$

$$
\begin{aligned}
& \text { SCHILDEREN kan hij niet } \\
& \text { paint.INF can he not } \\
& \text { 'He cannot PAINT' }
\end{aligned}
$$

Crucially, the inverted infinitives are not in some preverbal focus position, since they can cooccur with focused constituents:

\section{omdat hij DEZE boom schilderen wil} because he THIS tree paint.INF want

Since Dutch InfPs can invert, the configuration in (34) is wellformed in Dutch.

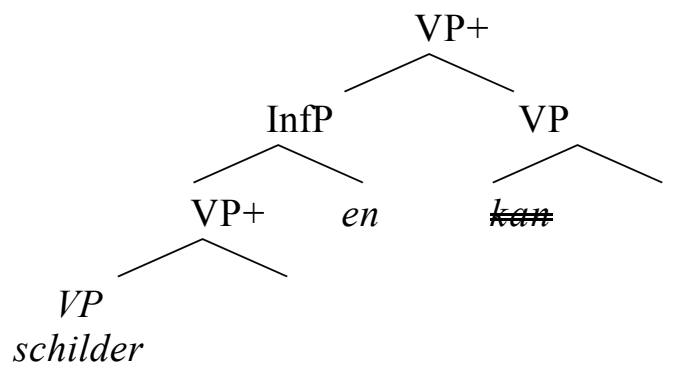

\subsection{Restrictions on inversion of infinitives.}

As is well-known from the Dutch literature ${ }^{11}$, there are curious restrictions on inversion of infinitives. These restrictions do not hold for other categories of $\mathrm{VP}+\mathrm{s}$, notably for remnant $\mathrm{VP}+\mathrm{s}$, an important fact given our perspective. The restriction can be formulated as follows (Broekhuis 1992):

(35) Infinitives may invert iff they are in a V1 V2 environment, where V1 is a tensed restructuring $\mathrm{V}$, and $\mathrm{V} 2$ is a bare infinitive (which itself does not restructure with an infinitive)

A discussion of the first restriction in section 3.2.1 will allow the motivation of the complexity filter. In section 3.2.2, it is shown show the other restrictions can be captured by the filter, modulo an independently motivated and necessary analysis of the infinitival marker te.

\subsubsection{No inversion of infinitives in V1 V2 V3 environment.}

Dutch infinitives may invert in V1 V2 environment, but not in V1 V2 V3 environments, whether it is full inversion ${ }^{12}$ :
a. zal willen schilderen V1 V2 V3
will want.INF paint.INF
'..will want to paint'
c. *zal schilderen willen *V1 V3 V2 will paint.INF want.INF


c. $\quad$ schilderen willen zal
paint.INF want.INF will

Or remnant $\mathrm{VP}+$ movement (climbing):

$$
\begin{aligned}
& \text { *...schilderen zal willen } \\
& \text { paint.INF will want.INF }
\end{aligned}
$$

Only English orders are allowed in this configuration.

$$
\begin{array}{ll}
\text {...zal willen } & \begin{array}{l}
\text { schilderen } \\
\text {...will want.INF } \\
\text { paint.INF }
\end{array}
\end{array}
$$

While remnant $\mathrm{VP}+$ climbing is excluded for infinitives, it is perfect for all other categories of small clauses, including participles:
a.
... op zal bellen
PP
up will call.INF
b. ...schoon zal maken clean will make.inf
AP
c. ...piano zal spelen piano will play.INF
NP
d. $\quad$.. naar LA zal vliegen
PP to LA will fly.INF
e. ... geschilderd zal hebben PartP ge. paint.PART will have.inf
f. *.. schilderen zal willen *InfP paint.INF will want.INF

The restriction on infinitives in VP+ climbing contexts is exceptional, as is the one-cycle restriction on inversion.

In sum, inversion and remnant movement of VP+ infinitives are fine in V1 V2 contexts, but excluded in V1 V2 V3 contexts. Moreover, English orders (38), do not show any effects of the length of the derivation. This strongly suggests that (36) and (37) are excluded by a restriction on allowable complexity, as discussed in the preceding section. We state this as a filter which takes the most complex attested case as representing the upper bound on allowable complex structure ${ }^{13}$. 
(40) Complexity filter on Spec, $V P+$ :

At the end of the derivation, the maximum allowed size of InfP dominating overt material in Spec, $V P+i s$ :

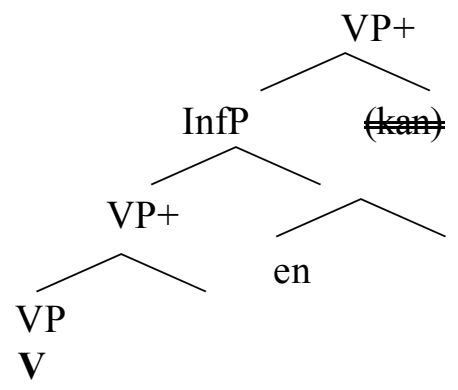

This filter allows for a single case of inversion (= inversion in V1 V2 environment), but excludes additional inversions (inversion in V1 V2 V3 environment). The most deeply embedded InfP will be dominated by structure that exceeds the allowed complexity, as the following representation makes clear:

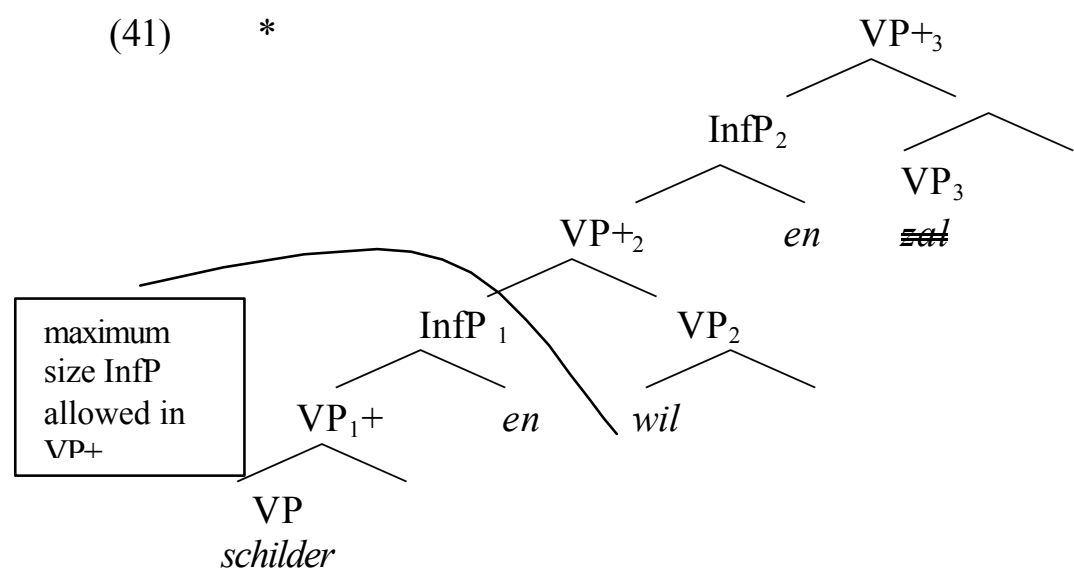

This filter also correctly excludes the ungrammatical string * zal schilderen willen (V1 V3 V2), and excludes climbing of infinitives (=remnant VP+ movement (37)):

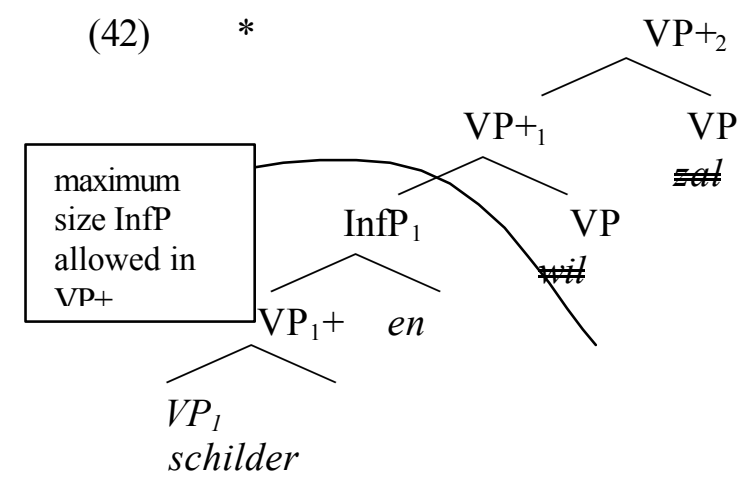

The filter says nothing about other cases of remnant $\mathrm{VP}+$ climbing. Indeed these $\mathrm{VP}+\mathrm{s}$ never contain InfP, and hence can continue to grow in complexity with each additional cycle, happily climbing up: 


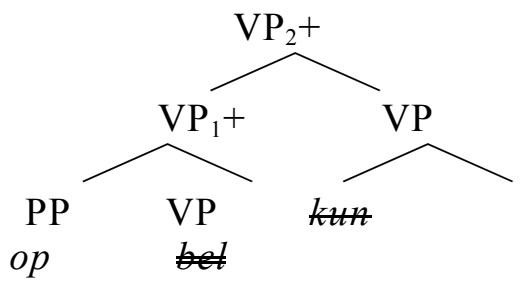

Finally, the filter allows English orders (V1 V2 V3), because these orders do not involve any complexity in Spec, VP+.

The next section briefly discusses how the complexity filter on VP+ captures the second restrictions in (35), modulo an independently motivated hypothesis about the infinitival marker te.

3.2.2 V2 must be a bare infinitive, and cannot be a te-infinitive Curiously, V2 must be a bare infinitive, and cannot be a te- infinitive:

(44) a. ...probeert te schilderen $\quad \mathrm{V}_{\mathrm{f}} 1$ [te V2] tries to paint.INF

\section{b. *...te schilderen probeert $\quad *$ [te $\mathrm{V} 2] \mathrm{V}_{\mathrm{f}} \mathrm{l}$} to paint.INF tries

German differs from Dutch in this respect: zu-infinitives do invert. The surface constituency is one in which the zu-infinitive has inverted, that is restructuring has applied (see Wurmbrand, 1998). In our analysis, then, the zu-infP is a VP+ remnant, which does not contain any of its dependent arguments

\section{zu schwimmen versucht German} to swim.INF tries

Finally, inversion is possible only in tensed (46a) but not in infinitival clauses (46b, c):
a. .. ...schilderen kan/kan schilderen ... paint.INF can/can paint.INF
b. het is niet belangrijk [ it is not important $\mathrm{C}$ to can.INF paint.INF
c. *het is niet belangrijk [ ${ }_{\mathrm{CP}} \mathrm{Om}$ schilderen te kunnen] * V2 te V1 it is not important $\mathrm{C}$ paint.INF to can.INF

Infinitives are again exceptional. All other VP+ categories, including participles, can (or must) move as remnant $\mathrm{VP}+\mathrm{s}$ to a position preceding te:

a. om Jan op te bellen 

b. om de kamer schoon te maken AP
$\mathrm{C}$ the room clean to make.inf
'to clean the room",
c. om piano te spelen NP
$\mathrm{C}$ piano to play.INF
d. (om) naar LA te vliegen PP
(C) to LA
to fly.INF
(om) geschilderd te hebben
C ge-paint-en to have.inf
(PartP)
f $*$ (om) schilderen te willen
$\mathrm{C}$ paint.INF to want.INF
$(* \operatorname{InfP})$

All these infinitival clauses contain te. The restriction can therefore be restated as:

(48) Inversion is impossible in V1 te V2 and te V1 V2 environments.

(48) can be further reduced to the previous V1 V2 V3 case, under the additional assumption that te is (or involves) a restructuring verb:

(49) te is a restructuring verb

This allows the following reformulation:

(50) Inversion is impossible in $\mathrm{V} 1_{\mathrm{te}} \mathrm{V} 2 \mathrm{~V} 3$ and $\mathrm{V} 1_{\mathrm{te}} \mathrm{V} 2 \mathrm{~V} 3$ environments

(50) now reduces to the general impossibility of inversion in V1 V2 V3 environments (3.2.1), which is captured by the VP+ complexity filter (40) in Dutch. Therefore the filter captures all restrictions elegantly and straightforwardly. Crucial of course for this account are the representations that the derivations generate: the queer restrictions on Dutch infinitives provide strong support for our approach, in so far as it provides insight into the simple pattern that underlies these apparently diverse restrictions.

Independent motivation for analyzing $t e / z u$ as a restructuring predicate comes from the position of $t e / z u$ within complex predicates. As is well-known, te must be preceded by remnant $\mathrm{VP}+$ small clauses (51a-e). (Dutch te cannot be preceded by remnant $\mathrm{VP}+$ that contains InfP (51f)):

(51) Dutch:
a. op te bellen
op to call.INF
b. schoon te maken clean to make.inf
c. piano te spelen
piano
to play.INF


d. naar LA te vliegen

to LA to fly.INF

e. gelachen te hebben /te hebben gelachen ge-laugh.PART to have.inf / to have.inf ge-laugh.PART

f. *[InfPgaan te moeten

go.INF to must.INF

Since restructuring predicates attract $\mathrm{VP}+$, the positioning of $\mathrm{VP}+$ reveals the presence of a restructuring predicate. That this is a remnant $\mathrm{VP}+$ must be connected to the property that te requires a bare InfP to its right (see section 3.4. as to how this property might be implemented by a particular complexity filter).

In sum, the proposed complexity filter targets the category InfP in a specific position (Spec, VP+); it only allows up to a certain size of (overt) InfP in VP+ at the end of the derivation, and captures the impossibility of inversion or climbing of infinitives in V1 V2 V3 environments. At the same time it allows remnant VP+ movement (e.g. climbing) of other VP+ categories freely.

\subsection{Crosslinguistic evidence}

Languages with similar verbal complexes as Dutch, but without the Dutch complexity filter on infinitives allow for inversion or climbing of the infinitive in precisely those contexts where Dutch excludes it. This is true for Hungarian, and German, where the paradigms are regular, and infinitives behave like other types of $\mathrm{VP}+\mathrm{s}$.

(52) Hungarian:

a. Inversion (K\&Sz 2000:73 ex (105))

Nem fogok dolgoznikezdeni akarni V1 V4 V3 V2

not will-1sg work.INF begin.INF want.INF

'I will not want to begin to work'

b. Remnant VP+ climbing (neutral clauses K\&Sz 2000: 74, ex (108))

Dolgozni fogok akarni

V3 V1 V2

work.INF will-1sg want.INF

'I will want to work'

(53) German

a. Inversion

weil PeterMaria anrufen können will VM4 V3 V2 V1

because Peter Maria up-call be-able want

'because Peter wants to be able to call up Mary'.

b. Inversion of zu-infinitivals

weil er zu schwimmen versuchte V2 V3.V1

because he to swim.INF tried

'because he tried to swim' 


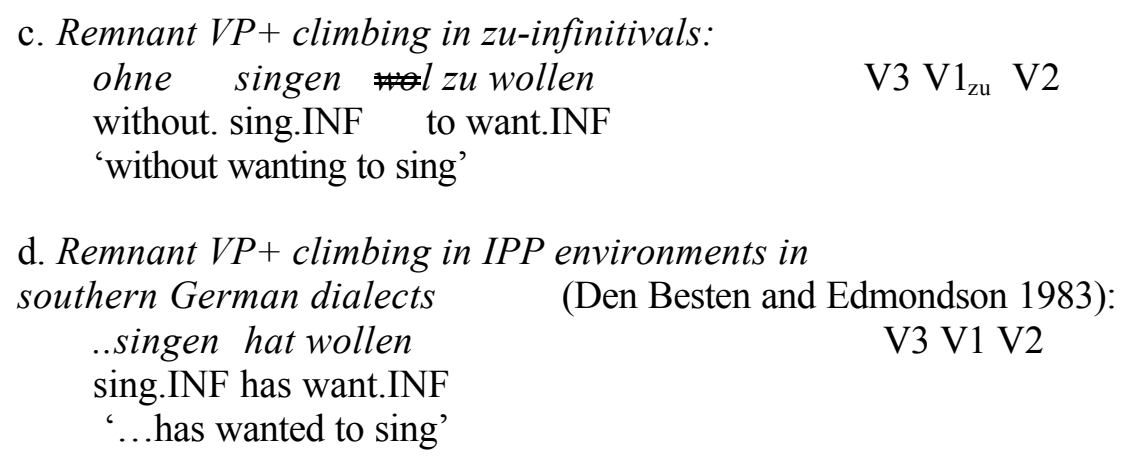

The restriction on infinitives in Dutch is thus exceptional. This is captured by a language specific complexity filter.

\subsection{Why alternative accounts fail.}

The case for the need of complexity filters will be strengthened in the absence of a reasonable alternative explanation. Moreover, if complexity filters of the type defended here are needed, $K \& S z$ proposal will be strengthened, since the relevant vocabulary for the filter is provided by the representations that K\&Sz's derivations generate. The goal in this section is to establish that other alternatives whether semantic, syntactic, or prosodic, or in terms of other types of surface filters, simply do not appear to be available ${ }^{\text {t4 }}$.

\subsubsection{A semantic account?}

Semantic accounts are doomed. How could a semantic account ever be able to capture the restriction on infinitives in Dutch? Why would the semantics have trouble with infinitives that are too deeply embedded, but not with equally complex participles, or other types of small clause predicates? Quite generally, the ordering of the verbs in the verbal complex has no discernable semantic effects. This is in part what makes verbal complexes both so difficult and interesting: they provide a unique window into the workings of the computational system.

\subsubsection{Syntactic accounts}

Could the restriction on inversion of infinitives be due to some violation of the basic computational system, say, the theory of movement? Dutch has both inversion of infinitives, and the necessary ingredients for inversion of infinitives, i.e. extraction of $\mathrm{VP}+/ \mathrm{InfP}$, and remnant VP+ movement. From a mechanical point of view, there is no way to express that infinitives can only invert once, whereas all other categories can continue to do so.

Since the restriction concerns InfP, a Case theoretic explanation might be invoked (Broekhuis 1997). However, it seems highly unlikely that Case theory is involved. First, Dutch infinitives do not have the distribution of Case marked DPs. They distribute like other small clauses when in preverbal position and like CPs when in postverbal position: this is exactly what K\&Sz' account captures. The potential motivation for Dutch infinitives needing Case therefore is weak, and must exclusively be based on the (sometimes) nominal nature of the infinitival ending en. Secondly, even if Case theory is in some way the culprit, it remains unclear how to capture the distribution of infinitives in a non-ad hoc fashion. A tensed restructuring verb should be able to somehow license "Case" on an infinitive to its left (therefore allowing for optional inversion), but an infinitival verb should not be able to do. A tensed restructuring verb should not be able to license Case on a climbed VP+, so as to exclude V3 V1 V2 orders. An infinitival restructuring predicate would have to license Case on a dependent infinitive in such a 
way that the infinitive shows up to its right. Finally, since nominal small clauses can occur in precisely those contexts in which infinitives are excluded ((59d) versus (59f)), a truly unique account will have to be given for infinitives in Dutch. These are serious problems, which to say the least will require a quite creative solution. However, the pursuit of this type of analysis misses an important generalization: the distribution of restructured infinitives is a subset of the distribution of small clause predicates on the one hand, and of CPs on the other. Our derivations capture this directly. Furthermore, the derivations provide all the necessary ingredients to express the restriction in an insightful fashion. From this point of view, then, there simply is no deep syntactic reason why these patterns are excluded. Complexity filters are in fact ubiquitous (for discussion, see section 3.). They enforce all kinds of quite arbitrary restrictions that are subject to microparametric and crosslinguistic variation. Of course, one would like to know why the complexity filter applies to the category of infinitives in Dutch. At the present stage of the theory, the answer cannot go beyond the fact that the filters captures the synchronic distribution of infinitives in Dutch, which happens to present this gap. How this situation could have arisen historically is an interesting but independent question.

\subsubsection{A prosodic account}

Den Besten and Broekhuis 1989, and Broekhuis 1992 argue that (36b) are to be excluded for prosodic reasons. Den Besten and Broekhuis observe that inverted infinites must carry primary stress. Small clause predicates in Dutch must carry primary stress as well. Only one primary stress is possible before the finite verb, where small clause predicates must occur. This is what excludes (36b), repeated here as (54) (primary stress is indicated by an acute accent and underlining the stressed syllable): both infinitives should be stressed, but this is excluded:.

$$
\begin{aligned}
& \text { *schílderen willen zal } \\
& \text { paint.INF want.INF will } \\
& \text { 'will want to paint' }
\end{aligned}
$$

Den Besten and Broekhuis 1989 argue that (54) is to be excluded in the same way as (55) (Broekhuis 1992:195 (43c)):

$$
\begin{aligned}
& \text { * dat je hem toch niet aárdig vínden kan } \\
& \text { that you him prt. not nice find.INF can } \\
& \text { 'that you cannot seriously consider find him nice' }
\end{aligned}
$$

Small clause predicates must receive primary stress in preverbal position, and hence cannot cooccur with an inverted infinitive, which needs primary stress as well. (54) and (55) clash with the prosodic patterns of Dutch, and that is why they are ungrammatical: the prosody of Dutch "filters" out these cases. This account does not carry over to 3-1-2 strings, since here there is no prosodic problem: there is only one inverted infinitive before the finite verb:

$$
\text { * } \frac{\text { schílderen zal willen }}{\text { paint.INF will want.INF }}
$$

Broekhuis 1992 tentatively proposes that this string is excluded by a "parsing" constraint, which is caused by the mixing up of infinitives.

Den Besten and Broekhuis's account is problematic on theoretical grounds. First, it is unclear why inverted infinitives require stress. Where does this requirement come 
from? Why wouldn't (54) with stress on the leftmost or righmost infinitive ne acceptable, or why wouldn't (55) be grammatical with stress on either the infinitive or the small clause predicate? Secondly, it is implausible that the V3(inf) V1 V2 strings in (56) are difficult to parse in Dutch: V3(part) V1 V2 strings (gezongen zal hebben 'lit. sang will have' or any type of SC(3) V1 V2 string (op zal bellen, 'lit. up will call') are extremely common and trivial Dutch patterns. Thirdly, such strings are perfectly possible in languages with similar verbal complexes (i.e. which allow remnant VP+ to be formed), as shown above, and therefore pose no processing difficulties in these languages.

Under Den Besten and Broekhuis's proposal, prosodic constraints reflect the surface patterns that Dutch allows: their prosodic constraint filters out those strings that never surface. However, this leaves unanswered the question how the stress patterns are determined: what exactly is the connection between syntactic representations and stress assignment (prosody) that yields these prosodic patterns? The null hypothesis, which I adopt, is that the syntax phonology interface is as simple and direct as possible. Any departure from this assumption needs careful argumentation, and historical arguments that show the syntax phonology interface is not direct should be subject to constant scrutiny and reevaluation with the continued development of syntactic theory. According to the null hypothesis, the prosody (stress patterns) derives from stress assignment principles in conjunction with the actual set of possible surface structures in a particular language. However, the prosody depends on the syntax. According to Cinque 1993, sentence stress universally appears on the most deeply embedded constituent. Cinque's theory works quite well with our representations, as I will discuss below, since by virtue of remnant XP movement, the hierarchical information remains encoded in the representations. This is indeed what seems to matter for sentence stress assignment in Dutch. The actual linear position in which the stressed element ends up is irrelevant.

. As Den Besten and Broekhuis 1992 point out, small clause predicates in Dutch receive primary stress. Small clause predicates are obligatorily in $\mathrm{VP}+$, because of complex predicate formation. The most deeply embedded constituent is the lowest predicate, which ends up in $\mathrm{VP}+{ }^{15}$. Small clause predicates therefore carry primary stress. Furthermore, in the presence of restructuring predicates, the most deeply embedded $\mathrm{VP}+$ is not the $\mathrm{VP}+$ of the restructuring predicate, but rather the most deeply embedded VP+ under a string of restructuring predicates. This is because restructuring predicates obligatorily form complex $\mathrm{VP}+\mathrm{s}$. Moreover, regardless of whether the derivations yield inverted orders, climbing orders or English orders, the most deeply embedded VP+ can be easily located in the surface representations because of remnant movement. Sentence stress should therefore show up on the mostly deeply embedded $\mathrm{VP}+$, regardless of the linear position of this VP+ ends up. As the following examples show this is correct.

$V P+$ contains an infinitive:

a. dat ik[VP+2Schílderen] wil/ wil [VP+2Schilderen]/wil kunnen [VP3schílderen] that I paint.INF want/ want paint.INF/ want can.INF paint.INF 'that I want (to be able) to paint'

b. dat zij schijnt te [VP3+schilderen] that she seems to paint.INF 'that she seems to paint' 


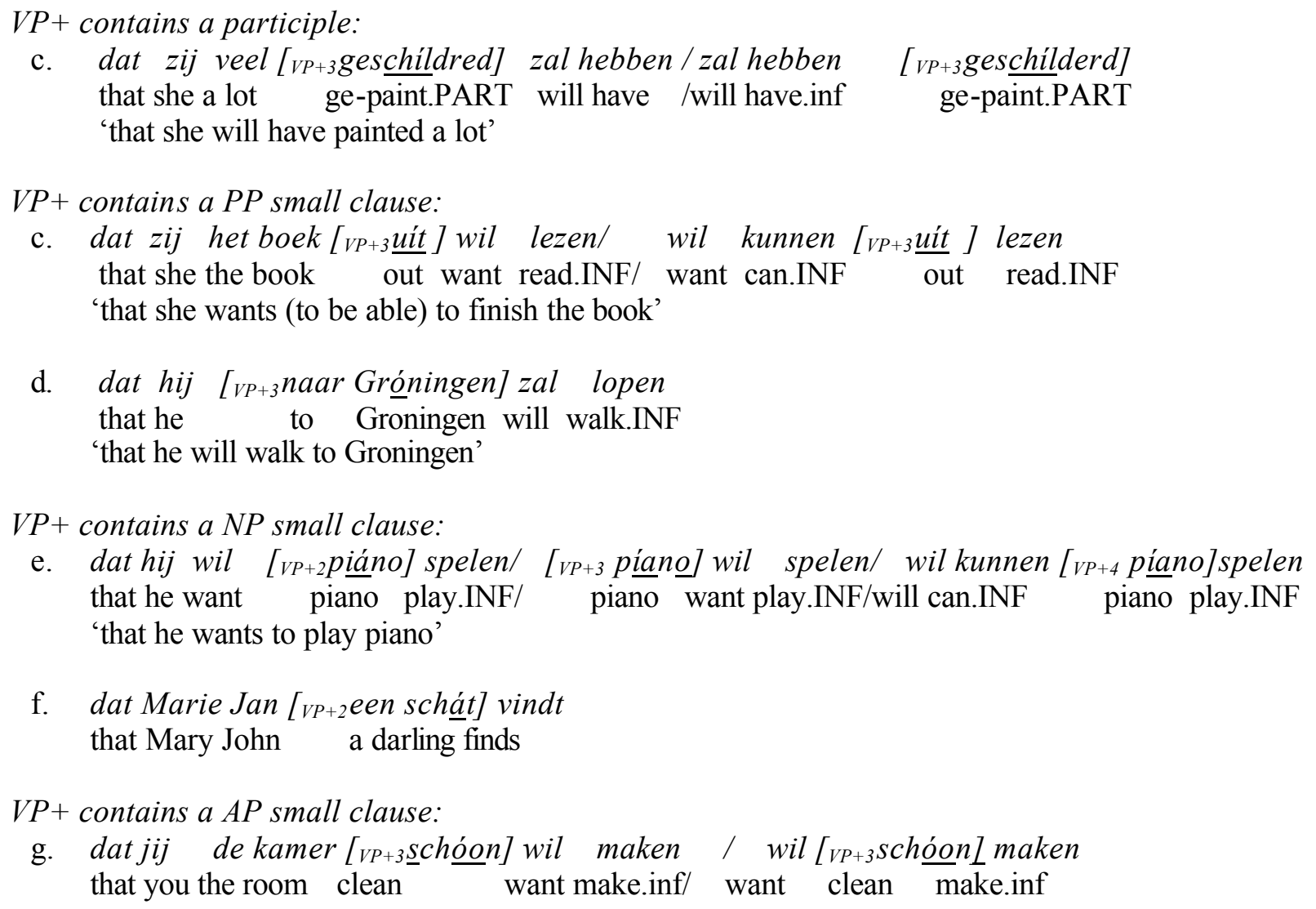

c. dat zij veel [VP+3 geschíldred] zal hebben/zal hebben [VP+3geschilderd] that she a lot ge-paint.PART will have/will have.inf ge-paint.PART 'that she will have painted a lot'

It is easy to see how Den Besten and Broekhuis's generalizations emerge from the representations in conjunction with Cinque's universal main stress assignment rule. Why do inverted infinitives obligatorily carry main stress and immediately precede the finite verb? This is because they receive main stress by virtue of being the most deeply embedded constituent, and because this is the only VP+ with an infinitive to survive in this position because of the complexity filter.

Two stressed inverted infinitives may not precede the verb:

$$
\begin{aligned}
& \text { * }[V P 3+\text { kómen. [VP2+willen]] zal } \\
& \text { come.inf want.INF will }
\end{aligned}
$$

This is because stress is located on the most deeply embedded VP+ (VP+3). Linear order is in fact irrelevant here. (59).is just as bad as (58):

$$
\text { * } \quad \begin{aligned}
& \text { zal willen } \\
& \text { will want.INF }
\end{aligned}
$$

Of the potential possible stresses, the only pattern to survive is b because of the complexity filter:
a. * kómen willen zal
OK for stress/*because of filter come.inf want.INFwill 

b. zal willen kómen
will want.INF come.inf
c. * kómen zal willen come.inf will want.INF
OK for stress/ OK for filter
OK for stress/*because of filter

From the present perspective then, there is no reason to assume a prosody driven account. On the contrary, our approach finds quite strong additional support, in so the representations potentially provide for a direct mapping from the syntax on the prosody.

\subsubsection{A surface filter account?}

At this point, K\&Sz's filter account seems to be the best available account. But once filters are admitted, one might wonder if a different type of filter account would not be sufficient, one for example that simply uses filters only sensitive to linear $\operatorname{order}^{16}$ (and not to hierarchical order).

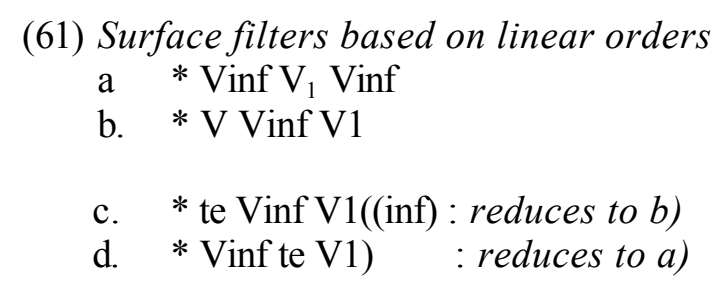

If the analysis of te as a restructuring $\mathrm{V}$ is adopted (61c) and (61d) further reduce to (61b) and (61a) respectively. These surface filters must make reference to the position of V1 (the highest V in a series) and to the category infinitive, since participles are not subject to the same restrictions. While these filters may work, they suffer from a general problem with filters: why these filters and not some others? These filters have no connection with the universal syntax of verbal complexes; they are independent from any other patterns of verbal complexes that a particular language may or may not show, and they have nothing to say about an independently necessary theory of sentence stress assignment. This type of surface filters should be rejected, since they are completely arbitrary. Filters should only be adopted, if they can be stated using the ingredients which are independently necessary. They should allow keeping the (indispensable) computational system optimally simple and general. The complexity filter precisely does this. It can only be stated on the representations that the derivations generate. These representations capture surface constituency, linear order and stress assignment of sequences involving restructuring predicates.

\section{Complexity filters.}

Complexity filters must be part of UG. We are in fact not the first to argue for the need of some complexity measure: our discussion is very similar to Stabler 1994 who argues for the need for a bound on allowable complexity. What is novel in our approach is the way this bound on "complexity" is expressed and integrated with the basic syntactic derivations and representations.

This section discusses other instances of complexity filters ${ }^{17}$, how one "diagnoses" the effects of particular complexity filters, and how these filters might be learned.

Given the discussion of Dutch, complexity filters reveal themselves as follows:

(62) a. "size-restriction "effects on particular Spec positions;

b. Restrictions on inversion; asymmetries between inverted structures (these grow with the length of the derivation, and might therefore show 
complexity effects), and English orders, which do not grow in complexity with the length of derivations;

c. restrictions on recursion;

d. "restrictions that are sensitive to particular categories (the Dutch filter applies to infinitives, not to participles)

Additional examples of (62a) are easy to come by, and are, I suspect, abundant, once it becomes clear what to look for. In general, complexity filters appear to capture wellknown facts that have so far resisted accounts.

As a first example, consider the placement of the infinitival markers te Dutch (the same analysis extends to German $z u$ ). An oustaanding problem is the placement of te/zu: it must be preceded by separable prefixes (remnant VP+), but followed by a bare infinitive (an InfP which contains only VP). Recall that te involves a restructuring predicate, which attracts a remnant $\mathrm{VP}+$ to its $\mathrm{VP}+$ (section 3.2.2), hence the placement of small clauses to the left of te.
a. op te bellen
up to call.INF
*te opbellen
to upcall.INF
b. schoon temaken clean to make.INF
*te schoonmaken
to clean-make.inf
c. naar LA te vliegen
to LA to fly.INF
*te naar LA vliegen to naar LA fly-INF
d. (om) geschilderd te hebben *te geschilderd hebben $\mathrm{C}$ ge-paint-en to have.inf to ge-paint.PART have.inf
e. *(om) schilderen te willen *te schilderen willen $\mathrm{C}$ paint.INF to want.INF to paint.INF want.INF

Observationally, te must be followed by a bare InfP, which cannot be embedded in a complex VP+. This restriction can be formulated as a complexity filter, which states that Spec, XP (=teP) minimally and maximally allows InfPs of the following size (see K\&Sz $166 \mathrm{ff}$ for a more detailed structure involving te; te will end up preceding $\operatorname{InfP})^{18}$.

Complexity filter on Spec, $X P(=t e P)$ : At the end of the derivation, Spec, $X P(=t e P)$ may not be more complex than:

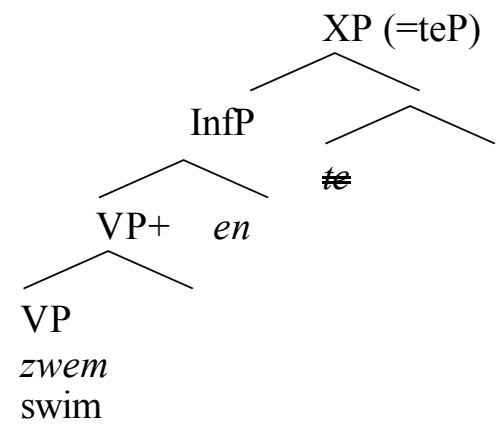


This filter allows full verbs (like swim) in VP+, as well as the VP of verbs that must form complex verbs (opbellen: to "call up") :

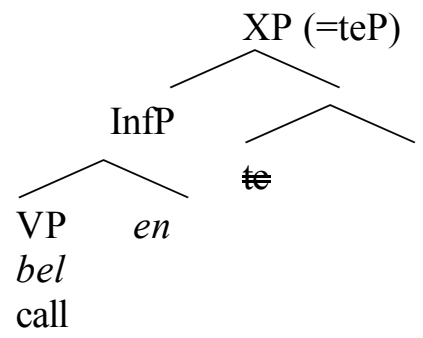

It does not allow xomple VP+,: the right-hand column in (63) violates the filter (64), as is illustrated for *te opbellen: (i.e. VP+ does not match the shape the filter allows)

$(66) *$

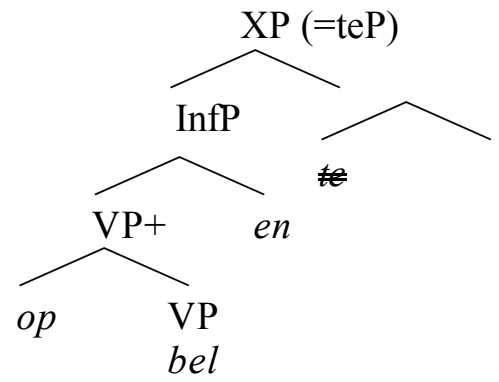

Because of (64), then, VP must split out of VP+ when it moves to InfP (pied-piping VP+ to InfP would invariably lead to a violation of (64)). As a result, te attracts a remnant $\mathrm{VP}+$ (cf the left hand column in (63)). In this way, complexity filters restrict the size of a pied-pipable constituent. A pied-piped constituent must be able to survive in the Spec position where it is pronounced. If the constituent is too complex, the constituent must be undone into smaller pieces. It is important to note that the filter holds of a particular Spec position: whether or not this position linear precedes or follows some overt item is irrelevant, as this example shows.

As a second example, we choose $\mathrm{V}$ to $\mathrm{C}$ movement in the Germanic languages: as is well-known, the finite verb that is attracted to the root $\mathrm{C}$ in Dutch cannot be accompanied by particles nor small clause predicates, but must "excorporate", i.e. be bare. This restriction can be implemented as a complexity filter on the Spec, $\mathrm{CP}$ position in root clauses (where C stands for the position that attracts the finite verb, most likely Rizzi's 1996 Fin. I analyze V to C movement as remnant VP movement to Spec, FinP, and assume adopting Rizzi 1996, that there are Topic and Focus projections higher than CP): 


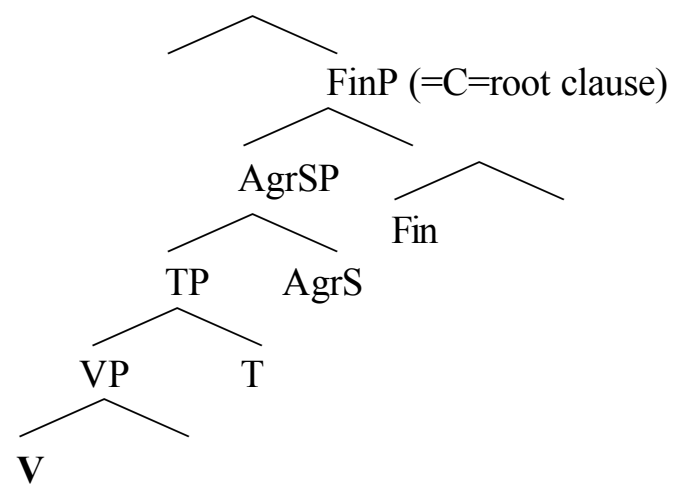

This filter forces excorporation, now conceived of as a (remnant) VP movement out of $\mathrm{VP}+$ in root clauses. Since this filter holds for a designated Spec position, more complex constituents are in principle fine in other Spec positions. This is desirable, since particles and small clauses cannot be pied-piped to $\mathrm{T}$ when the root $\mathrm{C}$ is present, but may be piedpiped in non-root environments (see K\&Sz:134 ff). Finally, the filter also prohibits material lower than V to be pied-piped, and thus in effect forces a VP remnantification. . Any phenomenon of this type can potentially be treated by complexity filters. Thus, the English auxiliary/do-support/main verb distribution might in fact be captured by complexity filters on Spec, NegP, and Spec, $\mathrm{CP}(+$ Root, $+\mathrm{Q})$.

A third candidate are German DPs. There are two positions where genitive DPs can surface in German (Longobardi 2001: 567):

$\underline{\text { Marias sorgfältige Beschreibung Ottos }}$ Maria's accurate description of Otto

However, there is a curious restriction on the leftmost genitive position: it may contain only bare proper names genitives or pronouns. No such restriction holds for the lower genitive position ${ }^{19}$ :

(69) ??Des Zeugens/*Dieser Frau/*Meiner Schwester / sorgfältige Beschreibung Ottos The witness'/ this woman's/my sister's /careful description of Otto

(70) Marias sorgfältige Beschreibung des Zeugen/ dieser Frau/ meiner Schwester Maria's careful description of the witness/this woman/my sister

This suggests a complexity filter on the leftmost genitive position along the following lines (internal structure of genitive DP is simplified): 


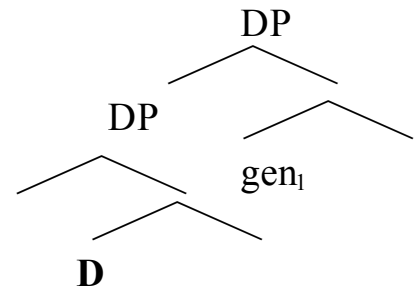

Because of this filter, only DPs with a raised proper name or a pronoun raised will survive. Any structures in which overt material lower than D is present will be filtered out.

A fourth and final case concerns restrictions on the internal structure of prenominal adjectives: as is well-known, pronominal adjectives may not be followed by phrasal material on their right, whereas postnominal APs show no such restriction ${ }^{20}$ :

$$
\begin{aligned}
& \text { a. this proud (*of his daughter) father } \\
& \text { b. this father proud of his daughter }
\end{aligned}
$$

These facts might be potentially captured by a complexity filter on some prenominal Spec position, which would prohibit overt material lower than A, though reasonable alternative accounts have been proposed for this particular case as well (Stabler 1994, Sportiche 1994).

All examples of complexity filters so far list the configurations in which overt material may occur. Restrictions on inversion in combination with the left right asymmetries of the Dutch type seem more difficult to find ${ }^{21}$. Stabler 1994 notices that morphological causatives, as opposed to syntactic causatives, in general cannot reiterate. If they can, as in Bolivian Quechua, there are restrictions on reiteration suggesting some sort of complexity bound. In our proposal, this restriction on iteration would be expressed by a complexity filter on inversion, similar to the Dutch filter.

An additional example of a restriction on inversion, can perhaps be found in English. Ross 1972 discusses the need for an "intelligent output condition" to capture the doubl-ing phenomena in English (also known as the doubl-ing filter):
a. He began singing
b. He began to sing
c. He is singing
d. $\quad *$ He is beginning singing
e. He is beginning to sing

Ross establishes that this phenomena only holds for a certain class of verbs taking -ing complements. These are exactly the verbs that trigger inversion in Hungarian and Dutch, i.e. these verbs belong to the class of restructuring verbs universally. If these -ing complement taking verbs (begin and be) are indeed universal restructuring verbs, they attract VP+. They thus have what it takes to form complex VP+s, which will increase in complexity depending on the number of cycles. It is interesting that the pattern in (73) shows a restriction on inversion which is exactly parallel to Dutch: one cycle of -ing embedding is fine, two cycles are disallowed (73d). Moreover, CPs (to CPs) do not seem to add complexity, presumably since they vacate $\mathrm{Spec}, \mathrm{VP}+$, and can therefore reiterate ( $I$ 
tried to begin to paint). These data suggests that a complexity filter, very similar to the Dutch filter on InfP rules out (73d). These data are doubly interesting, since restrictions on inversion, but no restrictions on CP recursion holds in English as well, even in the absence of left right asymmetries on the surface. It must therefore be the case that the visible left right asymmetry of Dutch is obscured by leftward movement of VP in English. Furthermore, "inverted" structures do not necessarily show up as nested structures (V2 V1), but can be "hidden" in V1 V2 structures as well, obscured by further movements..

In what other ways could a category sensitive complexity filter on inverted structures reveal itself? Staying with verbal complexes, the following phenomena would be diagnostic. Suppose that in some hypothetical language, restructuring predicates fall into two classes: whose which cooccur with verbal stems and those which cooccur with some other inflectional form (M). Suppose furthermore that the surface constituency corresponds to inversion, as in Hungarian:

$$
\begin{array}{r}
\text { a. } \left.\quad\left[\mathrm{VP}_{1}+\left[\mathrm{MP}_{\mathrm{VP} 2+} \mathrm{VP}\right]\right] \mathrm{VP}_{1}\right] \\
\text { swim can }
\end{array}
$$

The language has several restructuring predicates, which can all occur in the context in (74), yielding strings like the following:

$$
\begin{aligned}
& \text { a. swim-M want } \\
& \text { b. swim-can } \\
& \text { c. swim can-M begin. }
\end{aligned}
$$

However, certain combinations of these restructuring predicates cannot cooccur, even though such combinations are in principle possible and attested in other languages (i.e. want to begin to swim), while others can:

$$
\begin{aligned}
& \text { a. * swim-M begin-M want } \\
& \text { b. * swim-M begin-M want } \\
& \text { c. swim-can-M want }
\end{aligned}
$$

(76a, b) would be excluded by a complexity filter sensitive to the categorial feature of $\mathrm{M}$. Impressionistically speaking, many languages have cooccurrence restrictions of this type. Typically, then, any case in which several morphemes compete for the same slot but cannot cooccur, though these same morphemes can and do cooccur in other languages, should be looked at closely within this light, and this, regardless of surface order, as English doubl-ing suggests.

Quite generally, then, complexity filters are formulated on the representations that are generated; they hold for designated Spec positions, and express how much structure is allowed to dominate overt material, or what the shape of the overt material may be. So far, the discussion has focused on filters that state what the maximal allowable size dominating overt material is. We might raise the question if there are also filters that impose a minimal size. I believe there might be: this might actually be the proper way to express the bound morpheme property.

Complexity filters raise an important learnability question: how can the form of complexity filters be deduced from primary data without recourse to indirect negative evidence? I believe complexity filters can be deduced without recourse to indirect negative evidence. Indeed, they seem to reflect templates of the representations that the grammar imposes on the primary data. In an overt-movement type of theory, a large part of acquisition must consist in figuring out surface 
constituency: what size constituent is sitting in which projection. One of the tasks in acquisition might be to fix for each head how complex a constituent it allows in its Spec position, where complexity is calculated in terms of structure dominating overt material. These "templates" are a structural summary of the representations that the language learner imposes on the primary data, with the most complex template listed. It is rather natural to list these templates as part of the lexical properties of a particular head in the mental lexicon. An ungrammaticality judgment involving a size restric tion can be viewed as matching the representation against a particular mental template (a complexity filter), and recognizing that there is no match in one's internalized grammar. In this sense, learning these filters does not appear to require indirect negative evidence. The "acquisition" of templates is probably never quite finished: any change in the primary data can lead to a change in the internalized grammar. This latter point might be partly responsible for the gradual adjustments in judgments by linguists. Linguists actively working on verbal complexes, for example, tend to find more and more patterns acceptable over time. This is probably due to the fact that as linguists, we are creating our own primary data, which consist not only of possible patterns but also of impossible ones. We may finish by modifying our own internal templates. It is interesting that over time the tendency is to accept more, not fewer, patterns, indicating an increase, not a decrease, in allowable complexity. 
${ }^{1}$ Versions of this paper have been presented in Venice, Siena, and Florence in (1999), at the remnant movement workshop in Berlin (July 1999), and in seminar at UCLA (spring 2000). I would like to thank the audiences for discussion and suggestions. I would also like to thank an anonymous reviewer for helpful comments.

${ }^{2} 1-2-3$ in the text is used to refer to hierarchical order, with 1 the highest. Later in this paper, when illustrating particular derivations, I will use subscripted 1, 2, 3 to refer to the order of merger, with 1 the most deeply embedded.

${ }^{3} \mathrm{~K} \& \mathrm{Sz}$ assume a residue of head movement mainly to facilitate the mechanics of pied-piping (K\&Sz: 41).

${ }^{4}$ Cf. Hallman 1997, Sportiche 1994. K\&Sz suggest that each of Cinque's 1999 functional projections is a restructuring predicate in K\&Sz's sense (K\&Sz 2000: 224).

${ }^{5}$ Sportiche 1997 argues on the basis of selection and reconstruction that DPs do not directly merge with V; rather NPs merge with V and functional categories (number, determiners etc) are merged higher in the structure. (cf. also Kayne 1999 and 2000 on Cs and Ps). The LP(xp) positions in the structure above are most likely positions where functional material is merged, i.e. positions were DPs and PPs etc are "grown".

"There are also "marked" cases in German where VP moves (see section 3.3), and "marked" cases in Dutch where VP+ can move (wil opbellen, 'want upphone') The latter is sensitive to the internal complexity of VP+ (see K\&Sz 2000:159 ff).

${ }^{7}$ In the spirit of this paper, the bound property of en can be expressed as a filter on Spec, InfP, which will require overt material in Spec, InfP at the end of the derivation.

${ }^{8}$ This way of measuring complexity is sufficient for the discussion here. How to exactly calculate complexity remains a question for future research. What is clear is that is must be sensitive to overt categories, depth of embedding and types of categories. If it is only based on the structure dominating the most deeply embedded overt element, or on each overt category remains to be determined.

${ }^{9}$ See K\&Sz 2000: chapter 8, for more extensive discussion.

${ }^{10}$ More precisely, K\&Sz 2000 argue that this is a diagnostic criterion for PredP, which attracts VP+: PredP is a focusable category, (with DP, PP, AP). InfP, CP etc are not (K\&Sz, 2000:82).

${ }^{11}$ See, amongst others, Haegeman and Van Riemsdijk 1986, and Broekhuis 1992.

${ }^{12}$ The $\mathrm{b}$ order is sometimes cited as grammatical. This order is not part of my dialect. The filter predicts that the grammaticality judgments for V3 V2 V1 and V1 V3 V2, and V3 V1 V2 orders should cluster together.

${ }^{13}$ This filter is formulated as a filter on PredP in K\&Sz. Since I have left PredP out of consideration here, I have reformulated the filter here as a filter on VP+.

${ }^{14}$ A morphological account cannot be considered: we are clearly dealing with words, e.g. independently inflected verbs, and not with morphological units in the traditional sense.

Furthermore, in our proposal, there is no separate morphological component, and hence no special morphological properties.

${ }^{15}$ I simplify the discussion by leaving objects of transitive verbs out of the discussion.

${ }^{16}$ This type of solution was suggested by an anonymous reviewer.

${ }^{17}$ See K\&Sz 2000:192--194 for other complexity filters in Hungarian and Dutch.

${ }^{18}$ Participial ge- is subject to a similar filter (K\&Sz: 193).

${ }^{19}$ Thanks to Julia Merger-Morales for help with the German examples.

${ }^{20}$ Also relevant might be the pattern found in Nawdem (Gur): this proud father of his daughter. (Koopman, fieldmethods class, UCLA, 1998)

${ }^{21}$ The restriction on prenominal adjectives versus postnominal adjectives might in fact illustrate just such a case: "inversion" of AP would be $\mathrm{OK}$, but not when $\mathrm{AP}=$ proud of $D P$, which like 
Dutch CP must be move on and end up in a position where they eventually follow the $\mathrm{N}$ (like Dutch CPs).

\section{References}

Besten, H. den and Broekhuis, H. 1989. "Woordvolgorde in de werkwoodelijke eindreeks." GLOT 12, 79-137.

Besten, H. den and Edmonston J. 1983. "The verbal complex in Continental West Germanic". In On the formal syntax of Westgermania, Abraham W. (ed), 155-216. Amsterdam and

Philadelphia: John Benjamins.

Broekhuis, H. 1992. Chain government: Issues in Dutch syntax. Leiden: HIL.

Broekhuis, H. 1997. “Nogmaals Verb Projection Raising”. Tabu 27:1-27

Cinque, G. 1993. “A null theory of phrase and compound stress”. Linguistic Inquiry 24: 219-394.

Cinque, G. 1999. Adverbs and functional projections: A cross-linguistic perspective. New York: Oxford University Press.

Haegeman, L.and Riemsdijk, H.van 1986. "Verb projection raising, scope, and the typology of rules affecting verbs". Linguistic Inquiry 17: 417-466.

Hallman, P. 1997. "Reiterative Syntax". In Clitics, pronouns, and movement, J. Black and V. Motapanyane (eds).87-131, Amsterdam: John Benjamins.

Kayne, R. 1994. The antisymmetry of syntax. Cambridge, Mass: MIT Press.

Kayne, R. 1998. “Overt vs. covert movement.” Syntax 1: 128-191. [also in Kayne R. 2000]

Kayne, R. 1999. "Prepositional complementizers as attractors." Probus 11: 39-73. [also in Kayne R. 2000$\}$

Kayne, R. 2000. Parameters and Universals. New York.: Oxford University Press.

Koopman, H. and Szabolcsi A. 2000, Verbal Complexes Current Studies in Linguistics 34, Cambridge, Mass: MIT Press.

Longobardi, G. 1994. “Reference and Proper Names,” Linguistic Inquiry, 25.4: 609-665.

Longobardi, G. 2001. "The Structure of DPs", In The Handbook of Contemporary Syntactic Theory Baltin, M. and C. Collins (eds), p 562- 604. Malden and Oxford: Blackwell Publishers.

Rizzi, L. 1997 ."On the fine structure of the left-periphery” in Elements of Grammar. Haegeman L. (ed.) 281-337. Dordrecht: Kluwer Academic Publishers. [Also in Rizzi, L. 2000. Comparative Syntax and Language Acquisition, London: Routledge].

Ross, J. 1972 “Doube -ing” Linguistic Inquiry 3.2: 61-86.

Sportiche, D. 1994. “Adjuncts and Adjunction.” Key note address at LSRL, UCLA. 
Sportiche, D. 1997 "Reconstruction and constituent structure."Class lectures and lectures presented at MIT and various other places. .

Stabler, E. 1994 "The Finite Connectivity of Linguistic Structure" In Perspectives on Sentence Processing, Clifton C., Frazier L. and Rayner K. (eds), 245-266. Hillsdale: New Jersey.

Wurmbrand, S. 1998. Infinitives. PhD dissertation, MIT. 